\title{
El tratamiento de la luz en la poesía española: algunas calas
}

\author{
Adriana MARTINS-FRIAS \\ Universidad de Navarra \\ amartins@alumni.unav.es
}

\section{RESUMEN}

En este estudio se presenta un recorrido panorámico del tratamiento de la luz en ciertas obras de la poesía hispánica tradicional y contemporánea. En concreto, se hará referencia a algunas composiciones del Romancero hispánico, a la poesía de fray Luis de León y a la de poetas contemporáneos como Jorge Guillén y Claudio Rodríguez. Así, se pretende mostrar cómo la luz, dada su importancia en el desarrollo de la vida del ser humano, es un símbolo que trasciende su propio significado y permanece adaptándose a lo largo de los siglos en las obras literarias, definiendo así parte del imaginario cultural y literario.

Palabras clave: Luz, Romancero hispánico, Fray Luis de León, Jorge Guillén, Claudio Rodríguez, imaginario poético.

\begin{abstract}
This article shows a panoramic view of the traditional and contemporary approaches on the concept of light in Spanish poetry. In particular, it analyzes some compositions of Hispanic ballads, of the poetry of Fray Luis de León, and also of the poetry of contemporary authors such as Jorge Guillén and Claudio Rodríguez. On that basis, this paper shows how the symbol of light - given its importance in the development of human life - transcends its own significance while at the same time adapts itself to literary works throughout the centuries, thus defining part of the cultural and literary imaginary.

Keywords: Light, Hispanic ballads, Fray Luis de León, Jorge Guillén, Claudio Rodríguez, poetic imaginary.
\end{abstract}

Un análisis detenido del tratamiento de la luz en la poesía española muestra que este fenómeno natural, así como tantos otros también estudiados por la crítica literaria, constituye un «motivo lírico» o «tema» que permanece transformándose a lo largo de los siglos en las obras poéticas. Siguiendo a Claudio Guillén en Entre lo uno y lo diverso, al referirse a la tematización de la flor o la montaña, es de notar cómo en la literatura «el objeto, en efecto, o la vivencia se culturaliza y se tematiza 
desde las estructuras de una sociedad, por medio de sus cauces de comunicación y con destino a sus lectores y oyentes históricamente singulares» ${ }^{1}$. Así, el «tema»o «motivo» poético parece ser un mediador entre lo natural y lo cultural o lo prefigurado imaginariamente. Ahora bien, la luz, por su función en la naturaleza, por su importancia para el desarrollo de la vida del ser humano y su presencia continua en el quehacer cotidiano, es empleada de tal forma en algunas obras que no solamente es tematizada sino que, además, se convierte en símbolo ${ }^{2}$. Como se mostrará en este estudio, la luz se trata en poesía como un símbolo que trasciende su propia significación y permanece en las obras de forma constante consintiendo, dada su flexibilidad, connotaciones variadas e incluso opuestas.

Es necesario comenzar mencionando el relevante papel que ocupa la Antigüedad clásica en la posterior concepción del símbolo de la luz. La filosofía de Platón ejerce gran influencia en autores posteriores como Plotino o Pseudo Dionisio, autores neoplatónicos que «buscan con desesperación un puente que, tomando como punto de partida lo visible, les conduzca — a través de la metáfora de la luz - hacia lo invisible» ${ }^{3}$. En la luz se da la mezcla de lo material y de lo espiritual y se presenta, por tanto, como un elemento que cubre el abismo entre el mundo sensible y el de las ideas, entre lo físico y lo metafísico, entre lo palpable y lo absoluto. Así, lo Bueno, la Belleza, el Amor, la Verdad, serán valores totales que, en la corriente neoplatónica, aparecerán ligados a la luz o serán propiamente características emanadas de ella.

Junto con la tradición bíblica, el neoplatonismo tendrá gran influencia en la Edad Media ${ }^{4}$, cuando se generaliza de forma notable una línea de pensamiento teórico y

${ }^{1}$ C. Guillén (2013), p. 248.

${ }^{2}$ Señala Guillén: «Percibir una cosa como fértil pretexto en potencia, tematizándola y hasta convirtiéndola en símbolo, es un acto de atención situado y condicionado históricamente», C. Guillén (2013), pp. 242-243. En este estudio, además de respetar esta idea de «símbolo» como algo motivado históricamente, también se entiende como un tipo de «motivo» o «tema» lírico que trasciende el propio significado denotativo, es decir, que tiene un «excedente de sentido» (siguiendo a Ricoeur [1995], p. 68) manifestado a través de un primer sentido literal. La vinculación entre ambos sentidos solo se puede asimilar pero no comprender completamente, puesto que el símbolo está formado por una dimensión lingüística (similar a la metafórica) y otra no lingüística que resiste a cualquier transcripción lógica o semántica; es la dimensión de lo oculto, lo inalcanzable, lo absoluto.

${ }^{3}$ A. Puigarnau (1995), p. 13. Remito a esta obra para un estudio de la luz en algunos autores neoplatónicos.

${ }^{4}$ En esta época, es preciso tener en cuenta la influencia no solo de la tradición filosófica que parte de Platón y continúa con toda la tradición neoplatónica posterior de la mano de autores como Plotino o Pseudo Dionisio Areopagita, sino también es necesario apuntar la influencia de la patrística neoplatónica de San Agustín de Hipona o el influjo de todas las novedades científicas sobre el estudio de la luz que surgen en el siglo XIII, con autores como Roberto 
estético acerca de la luz. La crítica, en general, habla de una «teología de la luz»o de una «estética de la luz» que toma como referencia las reflexiones cosmológicas acerca de la naturaleza de la luz y las reflexiones de teólogos cristianos sobre pasajes de la Biblia en los que este símbolo es identificado con Dios ${ }^{5}$. Desde luego, esta tendencia crítica tiene como base esta última identificación: Dios como la luz misma y a su vez como creador y fuente de una luz que se extiende por el mundo y sobre los hombres.

Ante tal expansión de la luz en el pensamiento de la época, no dejaría de ser sorprendente que esta no se viera reflejada en la propia literatura. Patricia Pogal analiza la influencia de este concepto medieval de la luz en las composiciones del Romancero español. Recoge fundamentalmente referencias a la luz natural y al brillo de los astros, al fuego, a metales y piedras preciosas, al color blanco o a objetos que misteriosamente irradian su propia luz. Estas menciones reflejan el tratamiento de lo lumínico de los siguientes modos: como referencia a la voluntad de Dios sobre el destino humano reflejado en los astros; como símbolo de Dios y de rectitud y virtud morales; como alusión a lo bello y al amor; y como sinónimo de poder y nobleza. Señala Pogal que lo interesante de las referencias lumínicas del Romancero es que manifiestan una jerarquía medieval de la luz según la cual Dios es luz suprema y además máximo representante del Bien y de la Verdad, de la belleza y del poder; por extensión, «it appears that all persons and things God-like in any of these respects was associated in medieval Spain with Light, and depicted as shining in the 'Romancero'»'.

Por tanto, se concibe la luz como unidireccional, como proveniente solo de Dios: de ella todos participan en mayor o menor grado. Así, por ejemplo, tal y como Dios es «rey» del universo y es representado como luz divina, todos aquellos dotados de poder tenían en este sentido algo de divino y, por tanto, eran representados con gran resplandor físico, con metales preciosos cubriendo sus vestiduras, con colores claros (sobre todo el blanco) ${ }^{7}$, con armas relucientes, con castillos esplendorosos, etc. Tómense como ejemplos el «Romance de don García» ${ }^{8}$, donde se dice que este trae «saetas de oro en la mano», o el «Romance de Rosaflorida», donde se describe un

Grosseteste o Roger Bacon. Para más detalle, ver G. Torres Salinas (2013), p. 97 o I. Toste Basse (2002), pp. 229-237.

${ }^{5}$ Ver por ejemplo A. Puigarnau (1995), p. 146; V. M. Nieto Alcaide (1978), p. 15; o A. Ruschioni (1987), p. 10.

${ }^{6}$ P. Pogal (1995), p. 131. Asimismo, véase I. Toste Basse (2002), p. 231, que, al hablar de Pseudo-Dioniso Areopagita, se refiere a esta jerarquía en la concepción de la propia luz.

${ }^{7}$ Sobre este color, dice Chevalier: «El blanco, color iniciador, se convierte, en su acepción diurna, en el color de la revelación, de la gracia, de la trasfiguración que deslumbra, despertando el entendimiento al mismo tiempo que trascendiéndolo: es el color de la teofanía», J. Chevalier (1995).

${ }^{8}$ G. Di Stefano (2010), p. 307. 
castillo cuyos muros, plagados de metales preciosos y joyas, resplandecen tanto que incluso de noche parecen la luz del sol de mediodía .

Lo mismo ocurre con la descripción de la belleza de la niña blanca retratada en el romance « ¡Ay!, un galán de esta villa...» ${ }^{10}$ o con la de Guiomar en su romance, en la que el blanco y el oro ${ }^{11}$ son protagonistas:
Vérades cabalgar damas, - caballeros otro que tal;
ver cuál iba Guiomar - nadie lo sabría contar:
encima de una hacanea blanca - que en Francia no la había tal,
un brial vestido blanco - de chapado singular,
mongil de blanco brocado, - enforrado en blanco cendal,
bordado de pedrería - que no se puede apreciar,
una cadena a su cuello - que valía una ciudad.
Cabellos de su cabeza - sueltos los quiere llevar,
que parecen oro fino - en medio de un cristal,
una guirlanda en su cabeza, - que su padre le fue a dár,
de muy rica pedrería - que en el mundo no hay su par $^{12}$.

Si bien es verdad que el estudio de Pogal es interesante para la comprensión de las imágenes de la luz en el Romancero, es cierto también que en muchas ocasiones las referencias lumínicas en estos poemas son bastante breves y esporádicas, lo que hace que el símbolo de la luz no se vea explotado de forma más fructífera.

Ahora bien, el tratamiento medieval de la luz se extiende también al Renacimiento (que bebe igualmente de la tradición neoplatónica) adquiriendo ricas y nuevas connotaciones. Será principalmente Marsilio Ficino, representante e impulsor del neoplatonismo renacentista, la figura central de esta nueva visión de la luz. Frente a la concepción unidireccional, gradual, jerárquica y estática de la luz en la Edad Media, en la que esta siempre apunta a la sustancia divina presente en los elementos del universo, «para Ficino y el neoplatonismo renacentista la luz era vínculo del mundo, nudo por el que todo debe pasar y que se encuentra también en todo [...], sostén de la propia armonía del mundo, con capacidad para mediar entre lo terrenal y lo espiritual» ${ }^{13}$. Así, la luz se concibe como aquello que da uniformi-

${ }^{9}$ R. Menéndez Pidal (1980), pp. 93-94.

${ }^{10}$ R. Menéndez Pidal (1980), pp. 100-101.

${ }^{11}$ Como se ve, el oro es un elemento muy presente en los romances. Indica Ferber en su diccionario de símbolos literarios: «[G]old is the first of metals. [...] Its beauty and purity gave it divine status in biblical as well as classical culture; untarnishable and thus immortal, it belongs to the gods», M. Ferber (2000). Asimismo, Chevalier señala la relación del oro con la luz del sol y con la divinidad desde las tradiciones más antiguas; J. Chevalier (1995).

${ }^{12}$ F. J. Wolf y C. Hofmann (1856), pp. 290-305. El subrayado en este y el resto de poemas citados es mío.

${ }^{13}$ G. Torres Salinas (2013), p. 119. 
dad, coherencia, que relaciona las cosas en el universo, que atrae y que integra; en definitiva, que da armonía.

Esta idea de la luz como dadora de armonía está presente en la poesía de fray Luis de León. A la obvia influencia de la tradición bíblica sobre el fraile agustino se han de añadir, entre otras, las influencias de la tradición pitagórica, del platonismo, de San Agustín o del mismo Ficino ${ }^{14}$. Todo esto se traduce en su poesía en una concepción de la luz al estilo del neoplatonismo renacentista: esta es necesaria para el conocimiento del paisaje y para la visión de la unidad de los elementos que lo conforman; es aquella que no solo diferencia sino que además vincula las cosas, las unifica y les da orden. Como indica Estébanez Estébanez en su artículo sobre la estética de la luz en fray Luis de León:

En los colores y las formas el poeta ve la diversidad; en la luz, la unidad que vincula las cosas exteriores unas con otras. [...] La luz es el elemento que nos ofrece la diversidad de las cosas, pero que las mantiene, al mismo tiempo, en una constante tensión unitaria ${ }^{15}$.

Esta concepción de la luz como algo que dota de armonía al mundo en la poesía de fray Luis es ampliamente discutida en el artículo de Torres Salinas ${ }^{16}$, centrado en la expresión «luz no usada» del segundo verso de la «Oda a Salinas» ${ }^{17}$. En esta composición se desarrolla toda una alabanza de la música que también se concebía, según la visión neoplatónica y según se refleja en el pensamiento de Ficino, como ordenadora del universo. De este modo, la referencia a la luz junto a la música reafirma la noción de luz como dadora de armonía que subyace en la poesía de fray Luis. También en la oda VIII «Noche Serena. A Diego Oloarte» ${ }^{18}$ se refleja el orden del mundo a través de la unión de música y luz. Aquí el yo lírico contempla el cielo nocturno «de innumerables luces adornado» (v. 2), corte divina y «templo de claridad y hermosura» (v. 12), en clara alusión al templo de Dios. Ante la visión de «el gran concierto / de aquestos resplandores eternales, / su movimiento cierto, / sus pasos desiguales / y en proporción concorde tan iguales» (vv. 41-45), (y nótese aquí la unión de luz y música ${ }^{19}$ ) solo queda el lamento por la «bajeza de la tierra» (v. 62 ), esto es, por la limitación en la que se encuentra el alma.

\footnotetext{
${ }^{14}$ Ver G. Torres Salinas (2013), p. 105 y C. Estébanez Estébanez (1972), p. 293.

${ }^{15}$ C. Estébanez Estébanez (1972), pp. 292-293.

${ }^{16}$ G. Torres Salinas (2013).

${ }^{17}$ F. L. de León (2001), p. 94.

${ }^{18}$ F. L. de León (2001), pp. 118-123.

${ }^{19}$ Sobre esta unión de música y luz, es interesante el apunte de C. Cuevas, que habla de un «orfismo fono lumínico» en fray Luis, según el cual Cristo queda relacionado con Orfeo y así la luz y la música. Apunta: «curiosamente, los efectos del concierto de luz son en fray Luis los mismos que los de la música, y en eso coinciden la oda a Salinas, a Loarte y los
} 
Como se puede notar en la poesía del fraile, la contemplación de la naturaleza es esencial puesto que la percepción de su orden, su perfección y su belleza le lleva a entender también la grandeza de su Creador. De esta forma, la contemplación de la naturaleza iluminada por la luz, que vincula todas sus partes, le lleva también a conocer a Dios y unirse con Él. Sin embargo, si bien es verdad que concibe esta perfección y armonía de la naturaleza, es consciente también de la imposibilidad que tiene el ser humano de aprehender y comprender absolutamente el misterio y la verdad divina. Así, tal y como ocurría en la oda a Oloarte, en la oda segunda a Felipe Ruiz el yo lírico, con voz doliente, se queja de la limitación terrenal y escribe:

¿Cuándo será que pueda

libre desta prisión volar al cielo,

Filipe, y en la rueda

que huye más del suelo

contemplar la verdad pura sin duelo?

Allí, a mi vida junto,

en luz resplandeciente convertido,

veré distinto y junto

lo que es y lo que ha sido,

y su principio propio y ascondido (vv. 1-10) ${ }^{20}$.

Por tanto, el impedimento de conocer en profundidad lo que le rodea y la imposibilidad de acercarse más a Dios le llevan a anhelar el «vuelo al cielo» que le «libre desta prisión» terrestre, y que le permita ver de dónde vienen los misterios del mundo. Será en ese cielo en el que, junto a Dios, pueda conocer de forma absoluta todo el misterio divino («lo que es y lo que ha sido», «y su principio propio y ascondido»). La «luz resplandeciente» es aquí visión, es el conocimiento que le da acceso a la verdad, a la comprensión de lo esencial y de la diversidad unificada del universo («veré distinto y junto», escribe). «Ver» en esta oda es «conocer» y nótese cómo se repite ese verbo en futuro, clara referencia de que esta visión absoluta no puede ser alcanzada en el presente sino que queda reservada para la vida celestial futura: «Veré las inmortales / colunas, do la tierra está fundada» (vv. 16-17), «Y de allí levantado, / veré los movimientos celestiales» (vv. 51-52). Por tanto, la luz como símbolo de conocimiento absoluto está también presente en la poesía de fray Luis ${ }^{21}$.

Nombres de Cristo. Diríase que el agustino ha cristianizado el pensamiento órfico», C. Cuevas (1996), p. 378.

${ }^{20}$ F. L. de León (2001), pp. 128-129.

${ }^{21}$ La brevedad de este trabajo no permite el comentario de otros tantos autores clásicos que emplean la luz de forma notable. Así, se podría mencionar a san Juan de la Cruz, cuyo lenguaje místico, oscilante entre la luz, el fuego y la noche, la oscuridad, ejerce gran influencia en la poesía posterior (léase, por ejemplo, el poema Llama de amor viva, en S. J. de la Cruz [2009]), en el que la unión con Dios es transmitida con gran expresividad a través de imáge- 
El empleo de la luz en poesía como símbolo que trasciende el campo de lo denotativo permanece también en la poesía de algunos autores del siglo $\mathrm{XX}$, tales como Jorge Guillén o Claudio Rodríguez.

La obra de Guillén, Cántico, ofrece un largo repertorio de poemas donde se percibe cómo la luz constituye un símbolo clave que actúa como eje de sentido. García Berrio, que ha dedicado varios de sus estudios a la obra del poeta, destaca los «impulsos fundadores de desenlace, gracia de aparición: revelación, ascensión, concretamiento; concentración, manifestación, epifanía y todos los etcéteras en el movimiento de lo soterraño hacia la coincidencia de la luz» y la describe como «presente en la exaltación del gesto adquisitivo, del momento de luz, del exultante cenit de la comprensión, del éxtasis gozoso del eros. Eternidad perpetuante. Guillén del entusiasmo jubiloso, poder de la vida entre paréntesis, el día de Cántico figura inaugural del Guillén del entusiasmo» ${ }^{22}$. Por tanto, júbilo, entusiasmo, plenitud, exaltación, y junto a ellos la luz, son nombres que explican la expresión poética en esta obra.

De hecho, al analizar el tratamiento de la luz en algunos poemas de Cántico, se identifica su relación con la plenitud, con la exaltación de la vida. El yo lírico escribe:

Júbilo al sol. ¿De quién? ¿De todos? Júbilo.

$[\ldots]$

De veras se dirige a mi fervor

Esa $l u z$ sonriente en la penumbra

Del pavimento, bajo los follajes,

Sonriente en los claros de los troncos

Y de las hojas más privilegiadas,

Entre el verdor cortés y su ciudad.

Todo es prodigio por añadidura ${ }^{23}$.

Esta expresión de júbilo a causa de algo que embriaga viene acompañada por la reacción ante la manifestación de la «luz sonriente» que se dirige al «fervor» del sujeto como una epifanía o un prodigio. Esta luz es fuente de plenitud pero además (y como se percibe también en este poema en el que la luz recorre «la penumbra /

nes relacionadas con el fuego y con la luz); a Quevedo, con poemas como A Aminta, que imite al sol en dejarle consuelo cuando se ausenta (F. de Quevedo [1995]), en diálogo con la tradición petrarquista en la que es frecuente la caracterización de la amada a través de imágenes de luz; o también a Góngora con La fábula de Polifemo y Galatea (L. de Góngora [2010]), en donde, como señala García Díaz, «culmina el proceso de las posibilidades expresivas que tienen los contrastes de luz y color en la obra gongorina» (García Díaz [2001], p. 132).

${ }_{22}$ A. García Berrio (1995), p. 121.

${ }^{23}$ Poema titulado «Además», J. Guillén (1987), pp. 136-137. 
Del pavimento», «los claros de los troncos», etc.) da armonía, perfección, orden en el universo, tal y como ocurría en la poesía renacentista de fray Luis de León. Y este tipo de luz armónica, que continúa con el legado neoplatónico, no está solo presente en la poesía de Guillén sino que también se muestra en la obra de otros poetas coetáneos como Pedro Salinas o Vicente Aleixandre. Si bien es verdad que en la obra de estos dos últimos predomina la relación entre el amor (y la amada) y lo luminoso ${ }^{24}$ también es cierto que, como apunta $\mathrm{M}^{\mathrm{a}}$ Ángeles García Díaz, en la poesía de estos autores:

la luz [...] no es solo símbolo de la belleza de la amada - aunque lo sigue siendo, y mucho - sino que creemos que lo mismo que la música simbolizó el mundo armónico en el Renacimiento y el Barroco (ej. «Oda a Salinas» de Fray Luis de León), parece que es la luz la que pasa a simbolizar en esta generación - al menos en Salinas, Aleixandre, Guillén - esa armonía ${ }^{25}$.

García Díaz señala la música como símbolo renacentista de armonía, pero ya se vio más arriba que la luz también era concebida como vínculo armónico del universo. Así, en Guillén también se percibe una concepción amorosa del mundo pero entendida como aquella por la que el poeta busca la relación con las cosas, la solidaridad con ellas, con todo lo creado. Él mismo señala:

Nada sería el sujeto sin esa red de relaciones con el objeto, con los objetos. Ahí están de por sí y ante sí, autónomos, y con una suprema calidad: son reales. El despertar de cada durmiente recompone el careo que es nuestra vida: un yo en diálogo con la realidad. [...] Todo arranca de aquella intuición primordial. Una conciencia amanece en una conexión de armonía. Por supuesto, esta conexión ocurre solo entre un hombre más allá de su caos y un mundo más allá de su caos. Suficientes la salud y la libertad, el hombre se afirma, afirmando la Creación, valorada con una mayúscula. El así afirmado habrá de concluir gozosamente humilde: «iDependo de las cosas! ${ }^{26}$.

Y se lee en otro de sus poemas: «Me rige el universo. No hay desdenes / Luminosos de nadie ni son lujos / Las estrellas. ¡Oh luz, de mí dispones!» («Su poderío») ${ }^{27}$. El poeta, por tanto, se asombra ante la realidad que se le presenta como regalo y que le invita a participar de su plenitud. Y la luz se muestra como aquello

\footnotetext{
${ }^{24}$ Por ejemplo, pueden leerse las obras respectivas La voz a ti debida, P. Salinas (2003), o La destrucción o el amor, V. Aleixandre (1977).

${ }^{25}$ M. A. García Díaz (2001), p. 151.

${ }^{26}$ J. Guillén (1969), pp. 47 y 49.

${ }^{27}$ J. Guillén (1987), p. 289.
} 
que puede establecer esa red de relaciones solidarias entre el poeta y el universo ${ }^{28}$. No hay en la voz de Guillén una nostalgia de algo pasado o una añoranza de una plenitud futura, como sí ocurría en fray Luis. Para él la armonía con el mundo es presente, pues es en este tiempo actual cuando se alcanzan y se logran así trascender los propios límites. Como diría: "“Yo ajustado a mis límites" que en cierto sentido trascenderé. " ¡Soy / Del viento, soy a través de la tarde más viento, / Soy más que yo!"» ${ }^{29}$.

Asimismo, es necesario apuntar que en la obra de Guillén la luz también adquiere de forma frecuente una relación fundamental con la creación poética. La luz es la propia revelación de la realidad que espera ser plasmada a través de la palabra creadora $^{30}$. De este modo, no solo permite ver mejor la realidad, expresa plenitud, da armonía al mundo y significa la unión de este con el poeta, sino que es revelación en sí misma. «iLuz! Me invade / Todo mi ser. ¡Asombro!», se lee en su poema «Más allá»" ${ }^{31}$ en el que expresa con la luz del amanecer ese «choque-físico y metafísico» ${ }^{32}$, esa revelación luminosa. Ante esto, el poeta se siente embriagado tal y como se ve, por ejemplo, en el poema «Vida extrema ${ }^{33}$; o en $\langle$ Del alba a la aurora) ${ }^{34}$ :

¿Luz de luna? No es la luna

Quien va azulando la calle

${ }^{28}$ En Guillén no solo la luz, sino también el aire adquiere la función de dar armonía al mundo. El poeta, de hecho, dio primacía a este último elemento sobre el anterior y dijo: «La luz, naturalmente, está en todas partes, en todos los poemas... Pero yo he puesto más importancia en las palabras que se refieren al aire. El aire es ese elemento que me enlaza con el mundo, porque yo, cuando no tenga aire en los pulmones, pues... se acabó la historia. Por ejemplo, tiene mucha importancia el acto de respiración, elemental, fundamental, sin pedantería ninguna... Respirar, se trata de respirar, por ejemplo, cuando se habla de libertad yo no hablo más que de respirar, yo no hablo de política, hablo de respiración. Hay regímenes que se oponen a la respiración... pues esa sensación inmediata con el aire es en mi poesía importantísima», citado en M. Durán (1980), p. 219. La luz y el aire en la obra de Guillén son tratados en los artículos de M. Durán (1980) y C. M. Ziamandanis (1995), a los que remito para más detalle.

${ }^{29}$ J. Guillén (1969), pp. 52-53.

${ }^{30}$ Señala García Berrio: «La poesía de Guillén, como se sabe, representa la revelación de la realidad: maravillas concretas, esplendores de meseta luminosa, cima de la delicia... Y el poema: ritmo sentido que se desenlaza, palabras que lo cumplen y lo expresan, palabras absolutas, voces desnudas en realidad exentas de sintaxis», A. García Berrio (1995), pp. 120-121.

${ }^{31}$ J. Guillén (1987), p. 26.

32 J. Guillén (1969), p. 48.

${ }^{33}$ J. Guillén (1987), pp. 398-405.

${ }^{34}$ J. Guillén (1987), pp. 470-471. 
Por donde cruzo con ansia

De ver el sol en su trance

De regreso al horizonte

Mismo de nuestras verdades.

[...]

Del otro lado del aire,

Profunda región de gloria,

La Causa de veras ante

Mí saldrá. Quiero sentir

Cómo entre mis brazos nace

Para todos este día.

Si hay portento, no hay alarde.

Llegando está ahora el ser

Que de puro ser invade.

Pero la luz se me anuncia,

No se me entrega, distante

Por entre unas nubes donde

Sus grises van espesándose,

Casi oscurecidos bajo

Relieves a trechos casi

Morados, por fin con vetas

Chamuscadas. Muy bien arden

En torno los amarillos

De unos rayos entre avances

De acción apenas rojiza,

Señal de los inmortales

Fuegos. Estoy aquí para

Que a conciencia me arrebate

De una vez la primordial

Aparición. El instante

Me pide a mí que los ojos

Vean en claro sin éxtasis

El hecho -que sólo el alma

Con fe reconoce. ¡Salve! (vv. 1-6, 26-54).

El sujeto lírico describe las modulaciones de la luz al amanecer. Señala cómo, desde la primera luz que se percibe (una luz que «va azulando la calle» pero que no es luz de luna sino del alba), la luz se va extendiendo y percibiendo a través de diferentes colores: «Sus grises van espesándose», «a trechos casi / Morados», «Muy bien arden / En torno los amarillos», «De unos rayos entre avances / De una acción apenas rojiza». La luz, como revelación, no se entrega de repente sino que se anuncia, como si antes de llegar a su plenitud, se percibiera a través de ráfagas cambiantes. Ante esta anunciación, el yo lírico espera el momento de ver «el sol en su trance», cuando «a conciencia me arrebate / De una vez la primordial / Aparición», la aparición de esa luz cenital que lo invade todo. «iSalve!», se lee al final, una ex- 
clamación que transmite ese encuentro esperado, esa revelación de la luz que se expresa a través de la poesía.

El tratamiento de la luz como revelación también se encuentra en la obra de Claudio Rodríguez Don de la ebriedad, en la que se percibe una voz deseosa por conocer lo trascendente, la esencia de las cosas y por participar de la propia realidad a través de la experiencia poética ${ }^{35}$. Este deseo se muestra en las referencias continuas a elementos naturales que son vistos del modo más profundo (son constantes las alusiones a árboles, pájaros, astros, etc.). Desde luego, subyace aquí también esa idea de búsqueda de unión del hombre con el cosmos, de integración armónica de las cosas. Sin embargo, esa unión y percepción de lo absoluto no se dan de forma permanente en la poesía de Rodríguez; el poeta es consciente de sus propias limitaciones que le llevan a lamentarse, a la manera de fray Luis de León, y preguntarse: «Cuándo hablaré de ti sin voz de hombre. / Cuándo. Mi boca sólo llega al signo, / sólo interpreta muy confusamente» (I, V, vv. 23-25) ${ }^{36}$. En efecto, el sujeto poético se encuentra ante un estado de ebriedad que le es imposible de expresar a través del lenguaje común, tal y como ocurre por ejemplo en la poesía mística de San Juan de la Cruz. De ahí la irracionalidad que a veces se percibe en su discurso, o las exclamaciones o interrogaciones que muestran o bien exaltación o bien desconcierto ante lo real. Él mismo explica en su comentario a Don de la ebriedad:

Dos datos suficientes para orientar al lector. Poesía — adolescencia - como un don; y ebriedad como un estado de entusiasmo, en el sentido platónico, de inspiración, de rapto, de éxtasis, o, en la terminología cristiana, fervor. Claro está que no puedo reproducir dichas sensaciones ${ }^{37}$.

Sin embargo, a pesar de estas limitaciones, el poeta logra tocar lo intangible, aunque las revelaciones solo sean ráfagas de luz, aunque solo sean de forma súbita

\footnotetext{
${ }^{35}$ Dice el mismo poeta en el comentario a su obra: «Si la poesía, entre otras cosas, es una búsqueda, o una participación entre la realidad y la experiencia poética de ella a través del lenguaje, claro está que cada poema es como una especie de acoso para lograr (meta imposible) dichos fines», C. Rodríguez (1983), p. 13. Y más tarde añade: «Cuando Plotino reflexiona acerca de la "llamada Naturaleza es un alma, producto de un alma anterior que poseía una vida más potente...", nos puede llevar a lo que llamaría la presencia de las cosas y de su interpretación a través de la palabra, junto al canto», C. Rodríguez (1983), p. 14. Nótese esta referencia al filósofo griego neoplatónico Plotino que permite suponer que el propio Rodríguez también se vio imbuido de tales teorías neoplatónicas.

${ }^{36}$ C. Rodríguez (1983), p. 37.

${ }^{37}$ C. Rodríguez (1983), p. 14.
} 
y pasajera ${ }^{38}$. Ante la propia condición humana, ante la imposibilidad de expresar aquello que resulta inefable, ante la duda, el yo lírico siempre persiste en su búsqueda, en su camino, tal y como dice al final del poema «Canto del caminar», perteneciente al libro II de Don de la ebriedad: «Qué importa marzo coronando almendros. / Y la noche qué importa si aún estamos / buscando un resplandor definitivo. [...] Que cuando caiga muera o no, que importa. / Qué importa si ahora estoy en el camino» ${ }^{39}$. Es la búsqueda de ese «resplandor definitivo» lo que mueve al poeta y lo que le anima a seguir caminando. Así pues, la luz, si bien es verdad que funciona de diversos modos en la obra del autor (como plenitud absoluta, dicha, armonía del mundo ${ }^{40}$ ), también es la revelación que quiere ser materializada con la mayor precisión posible en la forma poética. La luz es en sí misma, como ocurría también en la poesía de Guillén. Léase el primer poema de Don de la ebriedad, en el que el yo lírico expresa el momento supremo de la revelación poética, cuando recibe la luz, «la claridad»:

Siempre la claridad viene del cielo;
es un don: no se halla entre las cosas
sino muy por encima, y las ocupa
haciendo de ello vida y labor propias.
Así amanece el día; así la noche
cierra el gran aposento de sus sombras.
Y esto es un don. ¿Quién hace menos creados
cada vez a los seres? ¿Qué alta bóveda
los contiene en su amor? iSi ya nos llega
y es pronto aún, ya llega a la redonda
a la manera de los vuelos tuyos
y se cierne, y se aleja y, aún remota,
nada hay tan claro como sus impulsos!
Oh, claridad sedienta de una forma,
de una materia para deslumbrarla
quemándose a sí misma al cumplir su obra.
Como yo, como todo lo que espera.
Si tú la luz te la has llevado toda,
¿cómo voy a esperar nada del alba?
Y, sin embargo - esto es un don-, mi boca
espera, y mi alma espera, y tú me esperas,
ebria persecución, claridad sola

\footnotetext{
${ }^{38}$ Como indica Prieto de Paula «la experiencia de plenitud ha de ser, por su misma intensidad y excepcionalidad, breve: una irrupción de luz sostenida en el tiempo ya no proporciona claridad, sino ceguera», A. L. Prieto de Paula (1986), p. 241.

${ }^{39}$ C. Rodríguez (1983), p. 52.

${ }^{40}$ Para más detalle, ver Prieto de Paula (1991), pp. 174-177.
} 
mortal como el abrazo de las hoces,

pero abrazo hasta el fin que nunca afloja ${ }^{41}$.

«La claridad viene del cielo» pues son la altura y lo celeste los que están relacionados con lo trascendente y lo absoluto ${ }^{42}$. Esta claridad es por sí misma, es una luz que ocupa las cosas y les da vida, por tanto, «se posa en lo natural, prestándole el halo luminoso que enciende plenamente sus contornos y su hermosura $»^{43}$. Sin embargo, además de esta idea de claridad como dadora de vida, armonía y hermosura, también se percibe una luz que está «sedienta de una forma / de una materia para deslumbrarla / quemándose a sí misma al cumplir su obra»: referencia clara a la poesía como plasmación de esa luz reveladora. Por tanto, la luz posibilita «la creación de una forma - el poema - en que encuentra cabida el ámbito de lo natural y el poeta que en él se inscribe» ${ }^{44}$. Esta claridad salva, llena, es algo que el yo lírico anhela y que su «boca» y su «alma» esperan (y nótese el poliptoton del verbo esperar que expresa ese deseo); pero también es «ebria persecución, claridad sola / mortal como el abrazo de las hoces, / pero abrazo hasta el fin que nunca afloja», pues lleva hasta un conocimiento último, a un resplandor tan impactante y final que destruye y lleva a la muerte. La luz puede ser también desintegradora.

Así, como se ha querido mostrar en este estudio, el motivo de la luz permanece en la poesía española conservando algunas de sus significaciones y creando también otras nuevas. Para entenderlas, es fundamental establecer un diálogo con la tradición literaria y tener en cuenta la influencia del neoplatonismo que, como se vio, llega hasta la actualidad. Luz y participación de Dios, luz y comunión armónica con el mundo, luz y conocimiento absoluto, luz y plenitud, luz y revelación son algunas de las relaciones aquí apuntadas. Con ellas se percibe cómo la luz física pasa a ser también luz «culturizada», luz «metafísica», luz «poética» que permanece indefinidamente como un símbolo primordial revelando variados sentidos. Desde luego, la potencialidad significativa que este elemento natural adquiere en la poesía ofrece un vasto campo de investigación que merece la pena seguir indagando con mayor profundidad.

${ }^{41}$ C. Rodríguez (1983), p. 33.

${ }^{42}$ La altura y la luz están frecuentemente relacionados, como apuntan Durand (2004), pp. 130-133 y Bachelard (1958), p. 59.

${ }^{43}$ A. L. Prieto de Paula (1993), p. 101.

${ }^{44}$ A. L. Prieto de Paula (1993), p. 101. 


\section{OBRAS CITADAS}

ALEIXANDRE, Vicente: Espadas como labios. La destrucción o el amor, Madrid, Castalia, 1977.

BACHELARD, Gaston: El aire y los sueños. Ensayo sobre la imaginación del movimiento, México - Buenos Aires, Fondo de Cultura Económica, 1958.

CHEVALIER, Jean: Diccionario de los símbolos, Barcelona, Editorial Herder, 1995.

CruZ, San Juan de la: Mística del siglo XVI. San Juan de la Cruz: Poesías. Subida del Monte Carmelo. Cántico espiritual. Llama de amor viva, Francisco Javier Díez de Revenga (ed.), Madrid, Biblioteca Castro, 2009.

CuEvas, Cristóbal: «Fray Luis de León y la visión renacentista de la naturaleza: estética y apologética», en Víctor García de la Concha y Javier San José Lera (ed.), Fray Luis de León. Historia, Humanismo y Letras, Salamanca, Universidad de Salamanca, 1996, pp. 367-380.

Di STEFANO, Guiseppe (ed.): Romancero, Madrid, Castalia, 2010.

DURÁN BLÁZQUEZ, Manuel: «Jorge Guillén, poeta del espacio y de la luz», en Evelyn Rugg y Alan M. Gordon (coord.), Actas del Sexto Congreso Internacional de Hispanistas, Toronto, University of Toronto Press, 1980, pp. 219-221.

DURAND, Gilbert: Las estructuras antropológicas del imaginario, México, Fondo de Cultura económica, 2004.

ESTÉBANEZ ESTÉBANEZ, Cayetano: «La estética de la luz en fray Luis de León», Revista de ideas estéticas, 30 (1972), pp. 285-296.

FERBER, Michael: A Dictionary of Literary Symbols, Cambridge, Cambridge University Press, 2000.

FERRÁN, Jaime María: «Del cielo a la tierra: la luz, la revelación y la cotidianidad en la poesía de Claudio Rodríguez», Letras Peninsulares, Fall - Winter (20062007), pp. 271-283.

GARCÍA BERRIO, Antonio: «Jorge Guillén: figuras de la imaginación», en Francisco Javier Blasco Pascual y Antonio Piedra (coords.), Jorge Guillén, el hombre y la obra: actas del I Simposium Internacional sobre Jorge Guillén, Valladolid, Universidad de Valladolid, 1995, pp. 119-126.

GARCÍA DíAZ, M Ángeles: Una aspiración a la luz: la poesía de Vicente Aleixandre, Kassel, Edition Reichenberger, 2001.

GóngOra, Luis de: Fábula de Polifemo y Galatea, Jesús Ponce Cárdenas (ed.), Madrid, Cátedra, 2010.

GuILlÉn, Claudio: Entre lo uno y lo diverso: introducción a la Literatura Comparada (Ayer y hoy), Barcelona, Tusquets Editores, 2013.

GuILlÉN, Jorge: El argumento de la obra, Barcelona, Ocnos - Llibres de Sinebra, 1969.

: Aire nuestro. Cántico, Claudio Guillén y Antonio Piedra (ed.), Valladolid, Centro de Creación y Estudios Jorge Guillén, 1987.

LEÓN, Fray Luis de: Poesías completas: propias, imitaciones y traducciones, Cristóbal Cuevas (ed.), Madrid, Castalia, 2001. 
MENÉNDEZ PIDAL, Ramón: Flor nueva de romances viejos, Madrid, Espasa Calpe, 1980.

NiETO AlCAIDE, Víctor Manuel: La luz, símbolo y sistema visual: el espacio y la luz en el arte gótico y del Renacimiento, Madrid, Cátedra, 1978.

POGAL, Patricia: Light Imagery in the Spanish Ballad, Maryland, Scripta Humanistica, 1995.

PRIETO DE PAUla, Ángel L.: «De la dualidad a la unión en la poesía de Claudio Rodríguez», en Literatura contemporánea en Castilla y León, Valladolid, Junta de Castilla y León, 1986, pp. 238-243.

: «La noche solar de Claudio Rodríguez», en La lira de Arión (De poesía y de poetas españoles del siglo XX), Alicante, Universidad de Alicante - Caja de Ahorros Provincial de Alicante, 1991, pp. 159-188.

: La llama y la ceniza: introducción a la poesía de Claudio Rodríguez, Salamanca, Universidad de Salamanca, 1993.

PUIGARNAU, Alfonso: Estética Neoplatónica: la representación pictórica de la luz en la Antigüedad, Barcelona, PPU, 1995.

Quevedo, Francisco de: Poesía completa I, José Manuel Blecua (ed.), Madrid, Biblioteca Castro, 1995.

Ricoeur, Paul: Teoría de la interpretación. Discurso y excedente de sentido, México, Siglo XXI, 1995.

RoDRÍGUEZ, Claudio: Desde mis poemas, Madrid, Cátedra, 1983.

: «A manera de un comentario», en Claudio Rodríguez, Desde mis poemas, Madrid, Cátedra, 1983, pp. 13-21.

RusChIONI, Ada: Poesia e metafisica della luce, Milano, Vita e Pensiero, 1987.

SAlinAS, Pedro: La voz a ti debida. Razón de amor, Madrid, Castalia, 2003.

TORRES SALINAS, Ginés: «Luz no usada y música estremada: poética neoplatónica de la luz en la oda a Francisco de Salinas, de fray Luis de León», Castilla. Estudios de Literatura, 4 (2013), pp. 93-136.

TOSTE BASSE, Inés Marta: «Metafísica y teología de la luz en el templo gótico», Revista Laguna, 10 (2002), pp. 225-241.

WOLF, Fernando José, y HofMAnN, Conrado: Primavera y flor de romances, Berlin, A. Asher \& Co., 1856.

ZiAMANDANIS, Claire M.: «Luz y aire en Cántico de Jorge Guillén: la tecnología contra el trovar», Castilla: estudios de literatura, 20 (1995), pp. 211-226. 